\title{
Erratum to: Electrical and Optical Characterization of Electron Beam Evaporated Indium Antimonide Thin Films
}

\author{
Rahul • A. K. Verma $\cdot$ R. S. N. Tripathi $\cdot$
}

S. R. Vishwakarma

Published online: 1 November 2012

(C) The National Academy of Sciences, India 2012

Erratum to: Natl. Acad. Sci. Lett. 35(5):367-372

\section{DOI 10.1007/s40009-012-0060-8}

Figure 7 has been published incorrectly in the original publication of the article. The correct version of the figure is provided below.

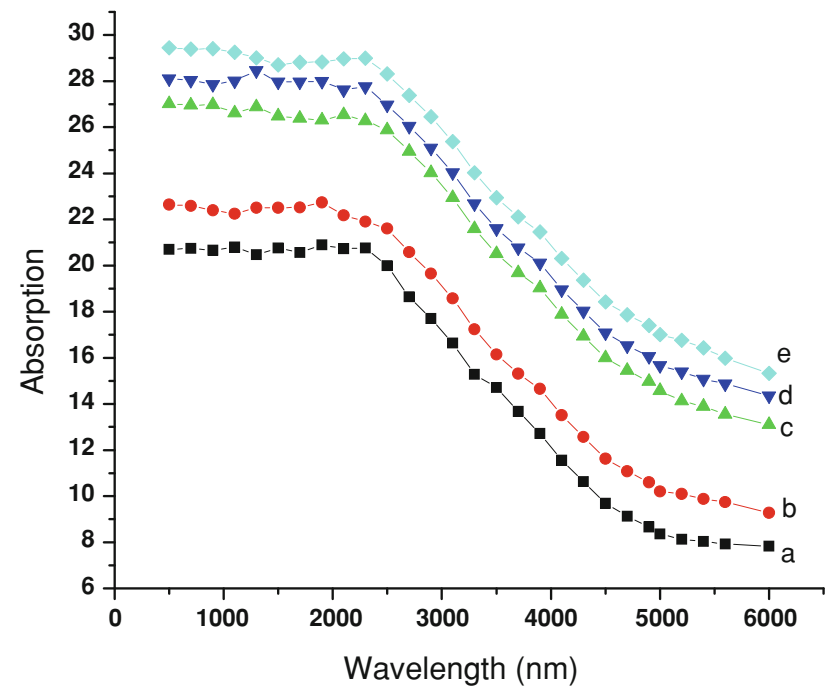

Fig. 7 Wavelength (nm) versus absorption spectrum of as deposited thin films for thickness a $700 \mathrm{~nm}, \mathbf{b} 800 \mathrm{~nm}$, c $900 \mathrm{~nm}$, d 1,000 nm, e $1,100 \mathrm{~nm}$

The online version of the original article can be found under doi: 10.1007/s40009-012-0060-8.

Rahul $(\bowtie) \cdot$ A. K. Verma · R. S. N. Tripathi ·

S. R. Vishwakarma

Department of Physics \& Electronics, Dr. R. M. L. Avadh

University, Faizabad 224001, India

e-mail: rhl.jaunpur@gmail.com 